Session 2555

\title{
Creating Community: A Pilot Program for Doctoral Students
}

\author{
Mara H. Wasburn \\ Purdue University
}

\begin{abstract}
Since the 1960s, the attrition rate of doctoral students has consistently been estimated at $50 \%$ nationwide. Explanations include: lax admissions standards, poor advising, student misunderstanding about the nature of graduate education, the process of graduate education itself, and lack of community. In 1999, to address the problem of lack of community, a Research Support Group was formed at Purdue University. Using a networking mentoring/learning communities model, the pilot program sought to provide support and guidance for doctoral students whose progress on their dissertations had stalled. In this paper, I present an overview of the program; some preliminary outcome data; a discussion of the program's effectiveness, foregrounding the voices of the participants; and some projections for the future.
\end{abstract}

Introduction

Stories about doctoral students who fail to complete their programs abound. Certainly Purdue University was no exception in 1998 when I received my doctorate. We had our "urban legends;" someone knew someone who knew someone else. I remember noticing that a woman who had been part of my statistics study group was not in any of my classes one semester. When I asked about her, one of my colleagues said she had taken the semester off. One semester stretched into two and then three. She did not return. Neither did the male colleague who had helped me with my dissertation data. Someone thought he had transferred, or perhaps not. He could not be certain. That colleague never returned either.

Since the 1960 s, the attrition rate of doctoral students has consistently been estimated at $50 \%$ nationwide ${ }^{1,2,3}$. The attrition rate for women students, especially those in engineering, science, and technology whose problems are exacerbated by their minority status, is estimated to be much higher, as they experience what is termed a "leaky pipeline" at every phase of their education 1,4 , 5,6 . The costs are measured not only in terms of the toll that failure to complete takes on the many students involved, but also in terms of costs to the university in lost faculty time, and doctoral programs whose very existence is threatened by being deemed unnecessary and/or ineffective ${ }^{7,8}$.

Explanations for the high attrition rate include: lax admissions standards, poor advising, student misunderstanding about the nature of graduate education, the process of graduate education itself, and lack of community. Lovitts argues that it is not primarily the background characteristics students bring with them to the university that affect their outcomes, but rather what happens to them after they arrive ${ }^{1}$. She maintains that the causes of attrition are deeply 
embedded in the organizational culture of graduate schools, as well as the structure and process of graduate education.

As it is presently constructed, graduate education is a system of filters designed to weed out the undeserving. However, several studies indicate that attrition is more closely linked to the lack of support systems than to academic factors $1,2,3,9$. Despite these findings, few if any formal support systems exist within departments to counteract the isolation that doctoral students, however bright, knowledgeable, and hardworking, often experience, especially during the dissertation phase of their education. Unless and until such support systems for doctoral students are put into place, it is impossible to determine with any degree of certainty whether or not it is, indeed, only the undeserving who are failing to complete their programs. The strong possibility now exists that capable, deserving students are also failing to complete their programs.

When doctoral students choose to abandon their programs, the absence of community is one of the determining factors in that decision ${ }^{1,10}$. The following describes the development of a pilot program that has the potential to determine if the creation of Research Support Groups for doctoral students will reduce their attrition rate nationwide. Although there are no engineering or science students in the pilot project, I would argue that the strategies described below could be employed within a supportive research lab.

\section{Background of the Research Support Group}

In 1998, I walked across the stage of Elliott Hall at Purdue University - West Lafayette to receive my $\mathrm{PhD}$ in Higher Education Administration. My family and friends were in the audience. It was a proud moment, and the end of a journey. As I advanced to receive my hood, I suddenly felt the tears welling up. So many of my women colleagues, the students with whom I had soldiered along in my program, had helped and supported me along the way.

We were all "women of a certain age," with University jobs and families. I was the new student and they were the veterans guiding me through the treacherous shoals of committee selection, course selection, departmental politics, and my nearly paralyzing fear of statistics. Suddenly, I was the one graduating and they were left behind. "Why me?" I asked myself.

The question haunted me in the days and weeks following my graduation. One major difference in the way I had handled my doctoral program was that I had identified my dissertation topic at the outset, so I was able to work on it while I took classes, directing each paper toward some portion of my future research. There was no period when I suddenly found myself alone with my dissertation, without the study groups and classes, without the supportive fellow travelers who are so much a part of the graduate school experience. By the time I took prelims, my dissertation was essentially completed. This must be the missing piece. If it was, I knew exactly how to repay my student colleagues.

In 1999, to address the problem of lack of community, I formed a Research Support Group at Purdue University. In the model I developed, a Research Support Group is a type of learning community ${ }^{11}$. Such groups build upon the idea that the successful long-term pursuit of academic goals is greatly facilitated by making and maintaining connections with others also 
pursuing those goals ${ }^{12}$. A Research Support Group also contains elements of "networking mentoring," which involves the participants in the mutual giving and receiving of information, coaching, support, and advice ${ }^{13,14}$. This pilot project sought to provide support and guidance for doctoral students whose progress on their dissertations had stalled, thus enabling them to complete their dissertations

As I saw it, if the group were to thrive, it would have to balance the personal and the professional needs of its members, which can be a fine line to walk. Sharing personal problems that can impede academic progress is important, but can easily devolve into gripe sessions. On the other hand, being too draconian about our academic expectations, e.g. meeting every week with a set number of dissertation pages to share, could risk our become part of the problem rather than part of the solution for our members, who already felt too pressured.

Research indicates that if group members have a part in making decisions that affect them, they become more fully invested in the group ${ }^{15,16}$. With that in mind, I listed some questions to which the members could respond at our first meeting:

1. How many members should we have?

2 Should members be from the same school and/or department?

3. How often should we meet?

4. What expectations should we have of one another?

5. Are we here only to review one another's work?

6. Do we invite the sharing of personal problems that might be interfering with a member's writing?

7. If we do discuss personal problems, how do we decide when enough is enough?

8. Do we need a facilitator or can we rotate the role?

9. Do we want or need speakers? If so, how many, how often, and on what topics?

10. Do we need an agenda for each meeting?

11. How should we respond to members who make no visible progress or do not attend regularly?

Armed with the questions and high hopes, I invited three women doctoral students to come together in an atmosphere of mutual support with a goal of helping one another to graduate. All of them accepted. They were enrolled in the School of Education from which I had just graduated. They all worked at Purdue, and had been enrolled in their doctoral programs between eight and eleven years, with little hope of actually completing their degrees.

\section{Organization of the Research Support Group}

At our first meeting, the members decided to meet twice a month over a brown bag lunch. As a graduate, I had more time, so I served as facilitator. I assumed the responsibility of sending out meeting reminders, obtaining material resources as needed, and trying to secure speakers on whatever topics members felt they needed expertise. We decided to accept anyone who wished to join, and to do all we could to encourage academic progress while leaving members time for their personal needs. 
There would be no formal agendas. Meetings would consist of discussing where each member was in her progress toward the PhD. Members would share materials and strategies they found helpful. If a member were having a particular a particular problem with her dissertation, such as difficulty identifying sources for her literature review or statistical problems with her methods section, the rest of us would brainstorm ideas for solutions. Hopefully the suggestions would be enough to get the member back on track.

As we began our regular meetings, we found that our group was proceeding apace. Those members having specific dissertation-related problems found a wealth of suggestions from their new support group. Those experiencing trouble with committee members or the university bureaucracy found sympathy, support, and practical suggestions based on others' experiences with the same committee member or other similar problems. Those whose families and/or employers were not supportive of their academic pursuits found a cohort of cheerleaders within the group. Speakers who had recently completed doctoral programs and graduated shared their strategies for success, offering still another level of support.

Within six months, the group had grown to 13 members; 11 of them were women. All but two were from the School of Education.

\section{Challenges and Successes}

Soon the group was facing some major difficulties. Attendance was our greatest struggle. With jobs, families, and community obligations, schedules were difficult to coordinate. Facing the group when a member had made no progress also proved daunting and caused some to skip meetings entirely. The two members from the School of Liberal Arts felt their needs were not being addressed and began to attend less frequently, so we returned to being a group from the School of Education.

In August 2000, just 18 months after the group had formed, one of the original three members graduated. In the preface to her dissertation, she cited the Research Support Group as one of the critical factors in the successful conclusion of what had been a 13-year struggle. Then a second member successfully defended her dissertation and graduated. Here were two successful outcomes within six months. The effect on the group was immediate. Attendance at meetings rose. Discussion because increasingly positive and focused on completion.

I decided to use the occasion to determine the value of the Research Support Group to its members and to gain insight into how it could be improved. I sent a brief questionnaire to the 13 past and present members. Nine members responded. The questions they were asked and their responses to those questions are discussed below. Table 1 below presents background data on the respondents. 
Table 1: Research Support Group Background Information

\begin{tabular}{llccc}
\hline Respondent \# & \multicolumn{1}{c}{ Major } & $\begin{array}{c}\text { Year } \\
\text { began }\end{array}$ & $\begin{array}{c}\text { Year of } \\
\text { prelims }\end{array}$ & $\begin{array}{c}\text { Year } \\
\text { graduated }\end{array}$ \\
1 & Higher Ed Admin & 1987 & 1994 & 2000 \\
2 & Higher Ed Admin & 1990 & 2000 & \\
3 & Higher Ed Admin & 1990 & 2000 & \\
4 & Special Education & 1991 & 1995 & \\
5 & Instructional Tech & 1991 & 2002 & \\
7 & Instructional Design & 1991 & 2000 & \\
8 & Educational Tech & 1991 & 2002 & \multirow{2}{*}{2000} \\
9 & Voc \& Tech Ed & 1994 & 1997 & \\
\hline
\end{tabular}

\section{Describe the role (if any) that the Research Support Group played in the pursuit of your PhD.}

It was a lifeline for me. I don't know any other way to put it. I was ignoring my dissertation and finding reasons not to work on it, why I didn't need a PhD. Now, I really believe I'm going to finish. I realize I need to for myself, even if I never use it.

So far, encouragement. Many things happened in my personal and professional lives that pushed the academic work to a back burner.

Increased clarity about process, support in terms of stages of dissertation, grounding, shared humor, networking, identification of ways to deal successfully with committees

A group of people who really understood what I was going through. Even though I didn't go very often, just keeping in touch with the facilitator helped keep me connected and grounded and moving toward my goal

Misery loves company, RIGHT! The Research Support Group has been valuable in terms of generating additional research ideas, issues to be concerned about when structuring prelims, committee composition, dissertation, etc.

Comrades at arms! That's the part that has meant the most to me. I felt so completely alone after classes ended. I just could not seem to make myself work on my proposal, never mind the dissertation itself. I just didn't want to think about it. Now, I'm interested. The group seems to like my topic. I'm moving again!

"Cooperate and graduate" was what you kept telling us. I hung onto that advice more times than you will know. Sometimes that was the only thing that got me through. 
The group helped me get over my writer's block. The discussions about my lit review gave me some new insights that allowed me to find the angle for organizing it. I honestly think I wouldn't have finished my dissertation without the support group.

\section{What advice would you give someone trying to form a Research Support Group?}

Set guidelines and expectations. The facilitator becomes discouraged when students don't attend for whatever the reason. The students feel guilty when other things interfere. Students who are 'pure' students may be able to meet regularly and move forward more rapidly. Think about the characteristics of the participants. Should Purdue staff be in one group and regular graduate students in another? Where would each be more comfortable?

Take a cohort approach. It helps to have someone that you are accountable to. So far, I've been taking courses, but I can see that once you get into the research, the structure is much looser. It can be a real plus to have others to whom you can discuss your issues and progress. It also helps to have a facilitator who takes a personal interest in each group member. The group does not function well without someone in that role, and most of the participants are too overwhelmed with work to take it on.

Start getting involved early in the program to learn from your fellow students. They give good advice and can really be helpful with those things that no one ever tells you. That way, you don't get stuck with saying, "I wish I knew that when..."

It's a FANTASTIC opportunity! I wish I had come more often. Things keep/kept getting in the way. I'm going to really try to get to each and every meeting now. I think if I had attended regularly, I would have graduated last summer when Mary did!

Consistency is the key. You should meet in the same place during the same day of the week, at the same time. Keep the agenda informal, but focused. Bring in outside speakers that will motivate and clarify process and procedures. Anything regarding best practices would be useful. I think the earlier you join the group-- even if you're still taking courses-the further ahead you will be in terms of your research.

Don't wait until you are in trouble before you join a group like this. If I had found this group earlier, I wouldn't have had many of the problems that have plagued my progress from the beginning. I finally feel that I'm on the right path. I just hope I can keep it up!

\section{What if anything would you change about the group?}

There is no question that it needs to be compulsory. If it were part of the doctoral program, we wouldn't be struggling with people who don't attend.

You don't want this to become too structured for fear that you lose people. I don't know if this could be done or helpful, but perhaps working time: spend time reading, writing, 
proofing, offering suggestions on the paper itself. Help with the library searches if people are stuck on that. Once some groups are established, let the grad students know about them early. Determine the most appropriate point in their work to join the group; after 15 hours of class work, at the beginning of the Advanced Research Methods course.

The group has no teeth. By that I mean that if you haven't done any work, you really don't have any consequences if you decide not to attend. You are free to come or not come as you choose. That needs to change.

It would be nice if there were some faculty from one's area of study represented on the committee.

The best approach would be to have schools and departments sponsoring groups like this. Then students would have no choice but to seek support. In my case, it was difficult to admit I needed help. I couldn't even admit it to myself.

I wish everyone would attend more regularly. It just helps to know that when you go there with a problem, you'll find the same people there, people you have come to know and trust.

There needs to be some mechanism by which everyone in the group would feel more invested in the group itself. Those who come can feel the caring. We have cried together, laughed together, shared the joys, and shared the sorrows. I worry because only two of us have graduated. Is there something more we could be doing?

\section{Please add any comments you would like to make.}

I wish there were more groups like ours. I think they're needed all over the University.

I think all doctoral programs need to take this issue seriously. I think that there need to be efforts made to get the research proposal incorporated into classes along the way, so that when you are finished with course work, you are ready to begin the data collection.

There shouldn't be a need for groups like ours. Programs should be more supportive of their students. The way graduate education is structured now, you are really at the mercy of your committee. Mine has been more a part of the problem than a part of the solution. What does that tell you about how much we need groups like this?

We need to reach out to more students around campus. It seems that the ones who need this group the most attend the least. Somehow, some way, we need to turn that around.

The support is critical. It's the process, not the product, that burns people out. The more cheerleaders one has, the better. The more often you have someone asking about your progress, the more likely you will continue to move forward. I think we all get caught up every once in awhile. This group allows you to regain focus and jump back on the horse. 
The Future of the Research Support Group

At the beginning of the Fall 2001 semester, we lost our first member, the only one to date to leave the group and abandon her studies. She had been a part of our group for nearly one year. It was particularly difficult for the rest of us to understand and accept, since it appeared to us that her dissertation was nearly completed. When I asked her why she was leaving after she had come so far, and what we could have done to better support her, she responded:

The major obstacle for me has been not having a supportive committee. No one checks in or seems to care whether I finish or not, and in some cases, I actually feel that they don't want me to finish. As soon as you finish coursework, you are completely alone. You have no deadlines to meet. You do not have the educational community to motivate you ... you go from a very collegial environment to one of isolation.

As for what you could have done, I don't think you could have done anything. Perhaps if there had been some kind of group for graduate students in my department or if I had found this group earlier, before the system had totally beaten me down, things might have turned out very differently ...

(Email correspondence, 24 October, 2001).

On a more positive note, a third member of our group will graduate in May, 2002, after a difficult, 11-year struggle to finish. There is every indication that more will follow her within the next two years. The Research Support Group, which began as four women from the School of Education, now has fifteen members, both men and women. We now have members from the Schools of Liberal Arts and Technology, as well as from Education. We continue to regard ourselves as an open community, available to anyone who can benefit from our support and encouragement.

\section{Recommendations and Conclusion}

The women and men at Purdue University who participated in this study clearly identified the need for a supportive community as key to completing doctoral degrees. Lovitts study discussed above is consistent with their contention ${ }^{1}$.

In nearly every case, those who sought to join the Research Support Group were already feeling the effects of their isolation and experiencing a variety of academic problems related to that isolation. Further research is needed to determine to what extent the development of a Research Support Group program that is proactive, rather than reactive, can change the culture of graduate departments from seemingly uncaring environments to supportive ones that will encourage students to complete their doctoral programs. Data are particularly needed on the situations of women in science, engineering, and technology programs whose problems are compounded by their minority status within their disciplines. Until support networks are in place, it is not possible to determine with any degree of certainty whether those students who fail to complete their programs are ill prepared or whether the graduate school environment itself contributes to their lack of success. It is my contention, based upon two years of working with the Research 
Support Group at Purdue University, that such groups can have a positive effect not only upon the attrition rate of doctoral students at Purdue, but upon attrition rates nationwide.

Bibliography

1. Lovitts, B. E. (2001). Leaving the ivory tower: The causes and consequences of departure from doctoral study. Lanham, MD: Rowman \& Littlefield.

2. Bowen, W. G., \& Rudenstine, N. L. (1992). In pursuit of the Ph.D. Princeton, NJ: Princeton University Press.

3. Garcia, M. E. (1987). Preventing the “all but thesis” phenomenon. (Doctoral Dissertation, Western Michigan University, 1987.) Dissertation Abstracts International, 48, 2089-B.

4. National Council for Research on Women. (2001). Balancing the equation: Where are women and girls in science, engineering and technology? New York: National Council for Research on Women.

5. Martin, J. R. (2000). Coming of age in academe. New York: Routledge.

6. National Academy of Sciences. (2000). Who will do the science of the future? A symposium on careers of women in science. Washington, DC: National Academy Press.

7. Schmidt, P. (1996, 29 March). Ohio Board of Regents deletes funds for 6 doctoral programs. Chronicle of Higher Education, p. A48.

8. Schmidt, P. (1997, 14 February). Sweeping reviews lead states to consider cutting many academic programs. Chronicle of Higher Education, p. A48.

9. Council of Graduate Schools Task Force. (1991). The role and nature of the doctoral dissertation. Washington, DC: Council of Graduate Schools.

10. Miller, W. D., \& Irby, B. J. (1999). An inquiry into the exigency of a beginning doctoral cohort in educational leadership. College Student Journal, 33 (3), 358-363.

11. Shapiro, N. S., \& Levine, J. H. (1999). Creating learning communities. San Francisco: Jossey-Bass.

12. Astin, A. W. (1985). Achieving educational excellence. San Francisco: Jossey-Bass.

13. Swoboda, M. J., \& Millar, S. B. (1986). Networking-mentoring: Career strategy of women in academic administration. Journal of NAWAC, 8-13.

14. Haring, M. J. (1999). The case for a conceptual base for minority mentoring programs. Peabody Journal of Education, 74 (2), 5-14.

15. Quinn, R. E. (1996). Deep change: Discovering the leader within. San Francisco: Jossey-Bass.

16. Schein, E. H. (1992). Organizational culture and leadership, $2^{\text {nd }}$. Ed. San Francisco: Jossey-Bass.

Biographical Information

MARA H. WASBURN, Ph.D. is an Assistant Professor of Organizational Leadership and Supervision at Purdue University. She holds a Ph.D. from Purdue University. She teaches courses in conflict management and gender and diversity in management, is coordinator of the coop and internship programs in OLS, and serves as faculty advisor to Women in Technology. Her research interests include mentoring and gender. 